\title{
Nanocomposite Trimethylsilyl-Modified Nafion/SBA-15 for Extraction and Analysis of the Volatile Compounds from Nepeta haussknechtii Bornm
}

\author{
Marzieh Piryaei ${ }^{1, *(D)}$, Saeed Yousefzadeh 2 (D) \\ Department of Chemistry, Faculty of Science, University of Maragheh, Maragheh, Iran \\ Department of Agriculture, Payame Noor University POBox19395-4697 Tehran, Iran \\ Correspondence: m.piriyaei@gmail.com;
}

Scopus Author ID 54389892400

Received: 1.03.2021; Revised: 7.04.2021; Accepted: 11.04.2021; Published: 26.04.2021

\begin{abstract}
Headspace solid-phase microextraction (HS-SPME) using a type of SBA-15 was made more hydrophobic by modification with ethoxy trimethyl silane to obtain a hybrid organicinorganic mesoporous nanocomposite, which then was impregnated with Nafion for the collection and detection of the volatile compounds of Nepeta haussknechtii Bornm. Experimental parameters, such as sample weight, extraction temperature, humidity effect, desorption time, and desorption temperature, were examined and optimized. Using HS-SPME followed by GC-MS, 42 compounds were separated and identified. HS-SPME has the benefits of small sample size, timesaving, cheapness, and simplicity, compared to hydrodistillation (HD). As we know, this is the first report on utilizing Nafion/SBA-15 fiber within solid-phase microextraction attached to headspace for assessing medicinal plant's volatile fraction.
\end{abstract}

Keywords: Nafion; SBA-15; Nepeta haussknechtii Bornm; solid phase microextraction.

(C) 2021 by the authors. This article is an open-access article distributed under the terms and conditions of the Creative Commons Attribution (CC BY) license (https://creativecommons.org/licenses/by/4.0/).

\section{Introduction}

The genus Nepeta (Lamiaceae) comprises about 300 species widely distributed in Eurasia. Nepeta species have been used for medicinal purposes. 79 species from the genus Nepeta can be found wild in various regions in Iran. Nepeta species are used in many countries' traditional medicine as a diuretic, diaphoretic, vulnerary, antitussive, antispasmodic, antiasthmatic, tonic, febrifuge, emmenagogue, and sedative agents. Many are used in folk medicine as bacteriostatic and disinfectants, as well as against eczema-type skin disorders. Some of the Iranian Nepeta species have been of great interest to Iranian folk and traditional medicines and are used to treat various disorders, such as some nervous, respiratory, and gastrointestinal diseases [1-4]. Pawliszyn and Arthur proposed solid-phase microextraction for the first time in the early 1990s. Their method is extensively utilized for extracting various semi-volatile and volatile organic compounds from biological, environmental, and food specimens. SPME is a suitably environmentally-friendly technique for determining the pollutants like essential oils in the plants and pesticides in real samples. In comparison to traditional methods like solid-phase extraction (SPE) and liquid-liquid extraction (LLE) approaches that are expensive, hazardous, and time-consuming to health as a result of the high volume of utilized toxic solvents, SPME represents a low-priced, simple, greatly sensitive, fast, solvent-free, and reproducible method 
for pretreatment of the sample. The micro-extraction solid-phase method is coupled with chromatographic systems. SPME integrates pre-concentration and sampling procedures into a single stage. Hence, it reduces the risk of analyte loss and contamination. The extraction result is based on the chemical and physical features of the fibers like porosity, surface area, and matrix nature. An appropriate fiber for SPME application should demonstrate high adsorption ability, good mechanical and thermal stability, as well as sufficient reproducibility [5-12]. Nafion can be utilized as an effective microextraction solid-phase coat for triazole pesticides. Nafion represents the low surface area. Hence, it grafts Nafion onto high surface area carriers or impregnating Nafion into porous substances indicating that the Nafion's surface [13-17] area restrictions should be overwhelmed [18-21]. SBA-15 is a 2D (two-dimensional) mesoporous silica standing out from other mesoporous silicas caused by its well-organized hexagonal mesoporous structure with tunable large uniform pore sizes (over $300 \AA$ ), high surface area (over $1000 \mathrm{~m}^{2} \mathrm{~g}^{-1}$ ), thick uniform silica walls, significant thermal stability, and its functionalization capacity by combining with organic linkers. Hence, SBA-15 as a nanomaterial offers a considerably greater surface area to volume ratio and promising superior extraction efficiency and capacity [22-24]. Following our former study on using nanomaterials and nanostructures like mesoporous silica in extracting volatile compounds of medicinal plants, we concentrated on establishing the Nafion-SBA-15 nanomaterials as the covering for SPME fibers. We propose to integrate Nafion resins over porous SBA-15 nanostructured substances to develop the solid-phase microextraction method.

\section{Materials and Methods}

Tetraethylorthosilicate (TEOS) as a silica source and poly (ethylene glycol)-block-poly (propylene glycol)-block-poly (ethylene glycol) (EO20-PO70-EO20 or Pluronic P123) as a surfactant were purchased from Aldrich (www. sigmaaldrich.com). Nafion (5 wt \% Nafion in water-alcohol solution) was supplied by Dupont (www.dupont.com). All chemical solvents were obtained from the companies Fluka or Merck (www.merckgroup.com). Helium, 99.999\%, was purchased from Roham Gas Co. (Tehran, Iran). The aerial parts of Nepeta haussknechtii Bornm (100 g) were harvested during the flowering season from the West of Iran. The plant materials were dried in the air and stored in sealed bags in a cool place.

\subsection{Synthesis of modified SBA-15.}

It was obtained by the same process used by Zhao et al. [6]. In short words, by dissolving 4 grams of the structure-leading agent P123 in 125 grams of $2 \mathrm{M} \mathrm{HCl}$ solution while stirring at $40{ }^{\circ} \mathrm{C}$, synthesizing the SBA-15 mesoporous silica specimen was conducted. Then, 9.12 grams of TEOS were added as a silicon source to the solution. After vigorous stirring at $40{ }^{\circ} \mathrm{C}$ for $24 \mathrm{~h}$, the resultant gel was transmitted to a Teflon-lined autoclave, and heating was performed at $100{ }^{\circ} \mathrm{C}$ for a further 48 hours. Followed by cooling to ambient temperature, recovering the solid was performed in the autoclave through filtering, rinsing, and drying at 80 ${ }^{\circ} \mathrm{C}$. Ultimately, calcination of the solids was conducted for $5 \mathrm{~h}$ at $550{ }^{\circ} \mathrm{C}$ for removing the organic surfactant. The surface -OHs of SBA-15 were silylated as: by pre-drying 2.6 grams SBA- 15 at $200{ }^{\circ} \mathrm{C}$ under vacuum for 12 hours, the addition of 3.5 grams of ethoxy trimethyl silane and 30 milliliters of dry toluene was conducted under Argon. Refluxing was performed for the mixture for a further 12 hours at $100{ }^{\circ} \mathrm{C}$. Then, filtering the modified SBA-15 materials 
and it was rinsed with anhydrous ethanol and toluene. Ultimately, drying the solid was conducted overnight at $80{ }^{\circ} \mathrm{C}$.

\subsection{Impregnating Nafion into modified SBA-15.}

To prepare the modified Nafion/SBA-15 nanocomposite, 30 wt. \%, Nafion was impregnated into the SBA-15 mentioned above and stirred at atmospheric pressure and $60{ }^{\circ} \mathrm{C}$ for 6 hours. First, the solid was dried for $12 \mathrm{~h}$ at room temperature in static circumstances, then the alcohols and water were thoroughly evaporated at $60{ }^{\circ} \mathrm{C}$ under a vacuum for further 12 hours.

\subsection{Preparation of the SPME fiber.}

Methanol was used to clean a piece of stainless steel wire (diameter of $200 \mu \mathrm{m}$ ) two times for 20 min within an ultrasonic bath, and drying was performed at $70{ }^{\circ} \mathrm{C}$. Epoxy glue was used to cover a centimeter of the wire, then immobilizing the modified Nafion/SBA-15 over the wire was performed. The covered wire was heated in an oven for $48 \mathrm{~h}$ to $50{ }^{\circ} \mathrm{C}$, gently scrubbed to eliminate nonbonded particles, and then it was fixed to the SPME holder tool. Ultimately, it was introduced into the GC injection port for cleaning the prepared SPME fiber and then conditioned in a helium environment for one hour at $300{ }^{\circ} \mathrm{C}$. The uniform coating layer's thickness (about $20 \mu \mathrm{m}$ ) was determined based on the differences between the uncoated and coated stainless steel wire diameters.

\subsection{The headspace SPME procedure.}

For HS-SPME analysis, 2.0 grams of the plant was transmitted to a 5-milliliter vial. Then, a rubber septum was used for dealing with the vial, and it was submerged into an oil bath with a constant temperature of $80^{\circ} \mathrm{C}$. Passing the SPME device's needle through the septum, its fiber was exposed to the plant's headspace atmosphere for 30 minutes. Then, the fiber was withdrawn into the needle and inserted into the $\mathrm{GC}$ injection at $260^{\circ} \mathrm{C}$ for $2 \mathrm{~min}$. Thus, the volatile flavor mixtures were completely desorbed and analyzed via GC-MS.

\subsection{Hydrodistillation procedure.}

By grinding $50 \mathrm{~g}$ of Nepeta haussknechtii Bornm's aerial parts dried in air-, they were exposed to hydrodistillation for 2 hours, utilizing a Clevenger-kind apparatus as commended by British Pharmacopeia. The plants were submerged in water while heating to boiling. Then, the essential oils were evaporated along with water vapor and ultimately gathered in a condenser. The distillates were dried and isolated over anhydrous sodium sulfate. Then, the dried oil was maintained at $4{ }^{\circ} \mathrm{C}$ until GC-MS analysis. The dried oil was stored at $4^{\circ} \mathrm{C}$ until analysis by GC-MS. Analysis of volatile compounds was carried out by direct injection 0.3 $\mu \mathrm{L}$ of the dried essential oil into the GC-MS.

\subsection{Apparatus.}

For determination, a Hewlett-Packard Agilent 7890A series GC armed with a split or splitless injector was used along with a mass-selective Agilent 5975C detector system. To run MS in the EI mode (70 eV), a carrier gas was used (helium, 99.999\%) with a $1.1 \mathrm{ml}$ min-1 flow rate. The PAHs were separated on a column (HP-5 MS, $0.25 \mathrm{~mm} \times 30 \mathrm{~m}$ ) with a $0.25 \mu \mathrm{m}$ film 
thickness. Keeping the column at $50^{\circ} \mathrm{C}$, then it incremented to $180^{\circ} \mathrm{C}$ at a rate of $15^{\circ} \mathrm{C}$ min- 1 and to $260^{\circ} \mathrm{C}$ at $20^{\circ} \mathrm{C} \mathrm{min}^{-1}$. For 5 minutes, it was then kept at this temperature. All the injections were conducted on the splitless mode for $2 \mathrm{~min}$, adjusting the injector at the temperature of $260^{\circ} \mathrm{C}$. The temperatures of an ion source, quadrupole, and GC-MS interface were respectively set at 230,150 , and $280^{\circ} \mathrm{C}$. To recognize the compounds, the Wiley $7 \mathrm{~N}$ Mass Spectral Library (Wiley, NY, New York, USA) was used. 7N (Wiley, New York, NY, USA) Mass Spectral Library. GC-MS was tuned before each analysis with HP Chem-Station Standard Spectra Autotune routine with perfluorotributylamine (PFTBA). A homemade SPME device was used for holding and the injection of the proposed fiber into the GC-MS injection port. Before its use for the SPME experiment, the fiber was heated at $100^{\circ} \mathrm{C}$ for $20 \mathrm{~min}$ in the oven and finally conditioned at $260^{\circ} \mathrm{C}$ in a $\mathrm{GC}$ injection port under helium gas for $2 \mathrm{~h}$ until a clean blank was obtained.

\section{Results and Discussion}

In this work, the reliability of Nafion/SBA-15 nanocomposite SPME fiber was investigated to extract the volatile compounds from the medicinal plant's headspace heated in the nonexistence of any solvent. It was found that a fiber's extraction ability is influenced strongly by the matrix-vapor phase mass transfer, conditioning the mass transfer and the headspace composition from the vapor phase to the fiber covering. Thus, it is rational to assess the effects of parameters on these equilibrium circumstances since it is challenging to find the equilibrium for all constituents of a complex matrix as an aromatic or medicinal plant due to their various polarity and volatility. To optimize the microextraction circumstances via the Nafion/SBA-15 nanocomposite SPME fiber when using the time optimization approach. The enhanced parameters included sample state and the quantity, extraction time and temperature, and desorption circumstances. Within the optimizing protocols, the peak areas of four main compounds existing in the medicinal plant recognized by HDtechnique were utilized for the optimizing process.

\subsection{Characterization of Nafion-SBA-15.}

Figure 1, shows the FT-IR spectra of SBA-15 and Nafion/SBA-15. The peak at 676 $\mathrm{cm}^{-1}$ represents the bending vibration of $\mathrm{C}-\mathrm{H}$. the peaks at 1083 , and $851 \mathrm{~cm}^{-1}$ are associated with the asymmetric and symmetric stretching vibrations of $\mathrm{Si}-\mathrm{O}-\mathrm{Si}$, respectively. The peak at $676 \mathrm{~cm}^{-1}$ represents the bending vibration of $\mathrm{C}-\mathrm{H}$. As can be seen in the spectrum of modified Nafion/SBA-15, the region of peaks mentioned has negligible shifting, which confirms the presence of Nafion in the structure of synthesized SBA-15. Peaks at 3437 and $1627 \mathrm{~cm}^{-1}$ are associated with the stretching and bending vibrations of hydroxyl groups. The peak at 2963 $\mathrm{cm}^{-1}$ shows the symmetric stretching, and $2931 \mathrm{~cm}^{-1}$ displays the asymmetric stretching of methyl groups. Peaks of $1083 \mathrm{~cm}^{-1}$ (asymmetric stretching of Si-O-Si) and at $845 \mathrm{~cm}^{-1}$ (symmetric stretching of Si-O) can be easily distinguished. The peaks at 3431 and $1630 \mathrm{~cm}^{-1}$ correspond to the stretching and bending vibrations of hydroxyl groups, respectively. The thermal stability of fabricated fiber at high temperatures of GC's injection port is an important parameter in SPME coatings. So TGA was investigated at atmospheric conditions to test the thermal stability of fiber (Figure 2). The weight loss between 250 and $500{ }^{\circ} \mathrm{C}$ was attributed to thermal decomposition. 


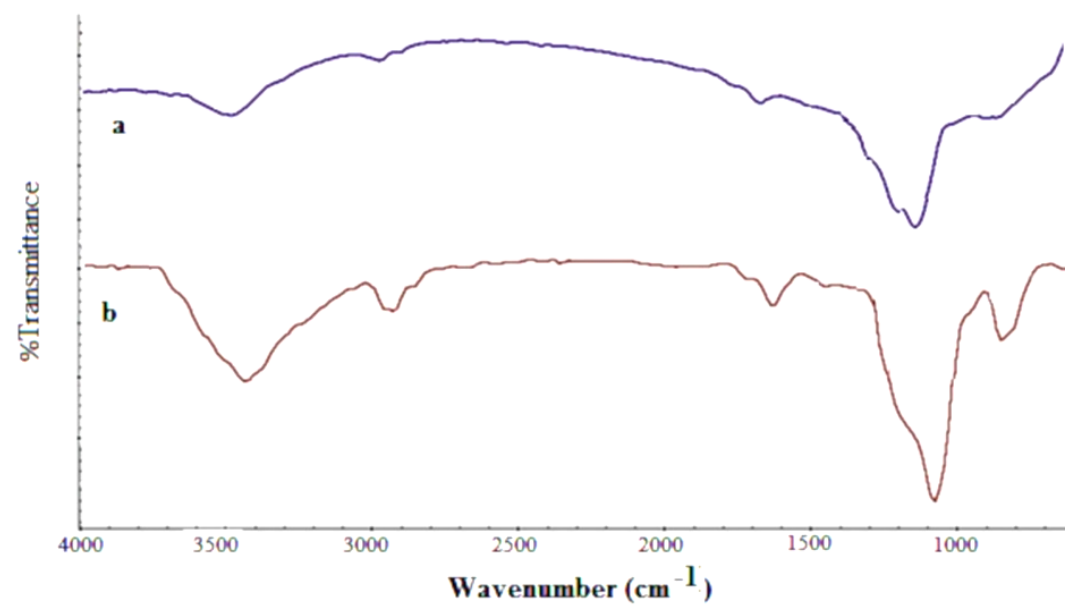

Figure 1. FT-IR spectra of (a) SBA-15;(b) Nafion-SBA-15.

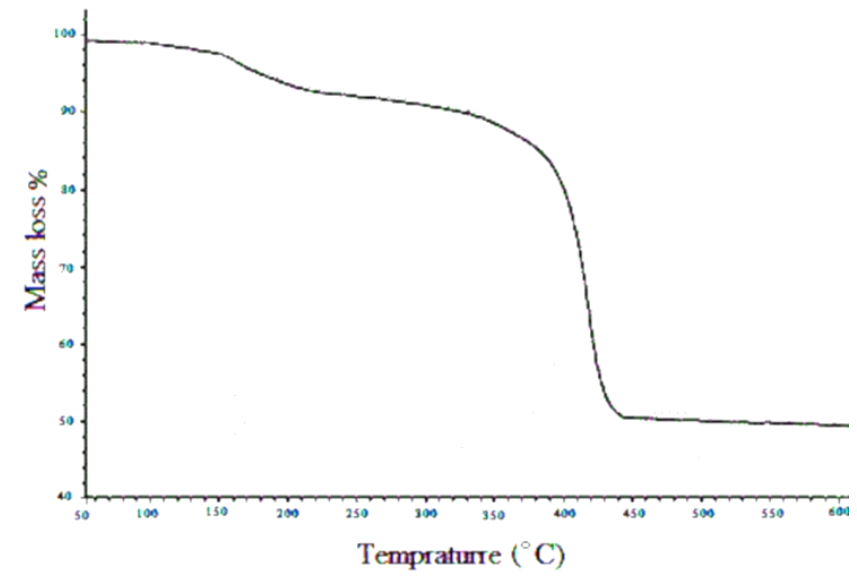

Figure 2. TGA pattern of the nanocomposite.

\subsection{Effect of temperature.}

The extraction temperatures were different within the range of $30-90{ }^{\circ} \mathrm{C}$, for which the results are presented in Figure 3. It represents the effects of extraction temperatures on the overall peak area of all the achieved compounds and the distinct peak area of the 5 target mixtures from Nepeta haussknechtii. The overall peak area or the separate peak area is incremented by the temperature to $80{ }^{\circ} \mathrm{C}$, and then it was reduced. The extraction temperature significantly affected the extraction since it can affect the compounds' distribution coefficients within the headspace and the sample as well as between the fiber and the headspace. Based on these findings, a temperature of $80^{\circ} \mathrm{C}$ was finally used for the current study.

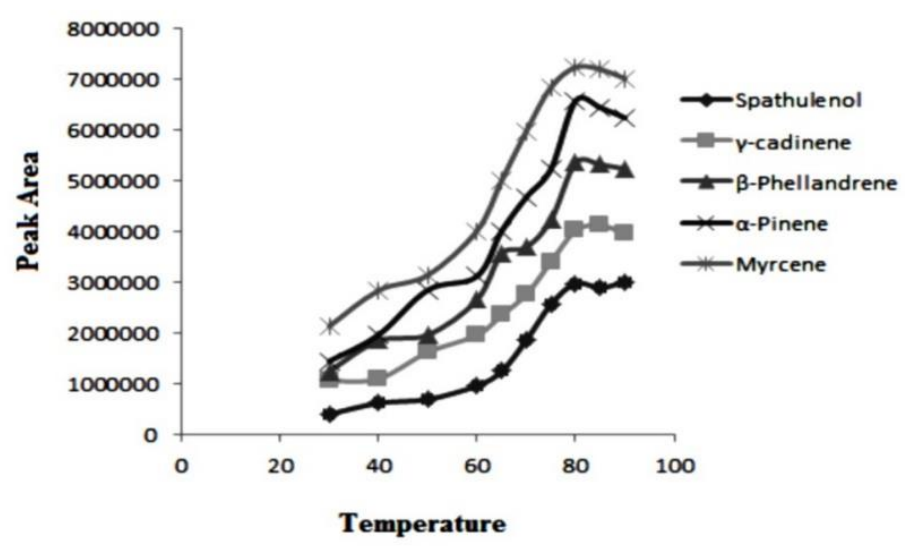

Figure 3. Effect of extraction temperature on the extraction efficiency. 


\subsection{Sample mass.}

Normally, analytes signals are incremented based on the sample size, however, extraction efficacy will be influenced by the further quantity of the specimen. Moreover, it was not indicated that a higher sample size leads to better results. For an HS-SPME process, a huge sample size sometimes leads to trouble for the sampling practice as a result of the sample powder's static adsorption to the fiber, particularly when using a finely powdered sample for the analysis. In the current study, the specimen quantity was different within 0.5-3.0 g. Fig. 4 shows the findings of the impacts of sample quantity on the total peak areas and the singular peak areas of the 4 target compounds. The total and individual peak areas incremented by increasing the sample quantity of $2.0 \mathrm{~g}$, just as expected, and then leveled off at a sample amount greater than $2.0 \mathrm{~g}$. A sample amount is often considered suitable for the analysis if it can satisfy the purpose's sensitivity.

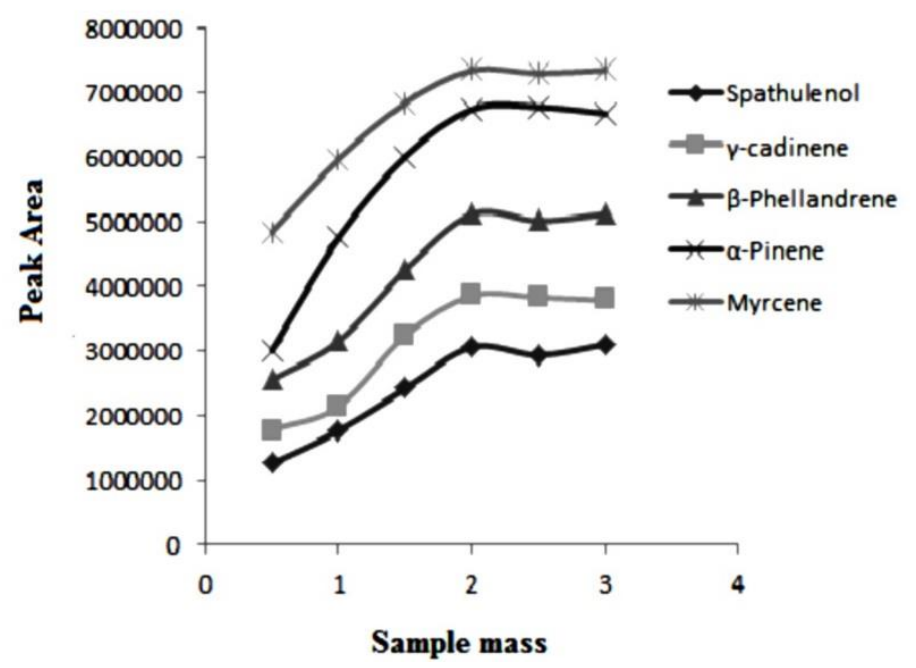

Figure 4. Effect of sample weight on the extraction efficiency.

\section{4. Effect of humidity.}

Water vapor (humidity) may affect the fiber capability at adsorbing the volatile compounds of Nepeta haussknechtii due to the Nafion/SBA-15 nanocomposite structure. Thus, the effects of humidity were investigated by adding various water quantities to the specimens in the optimized circumstances.

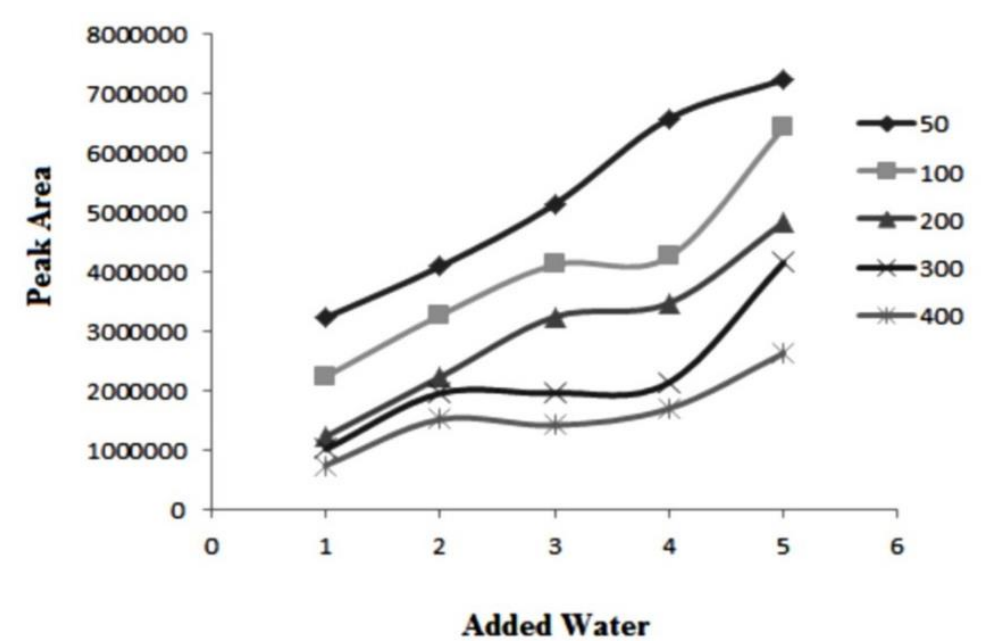

Figure 5. Effect of water addition on the extraction efficiency of the SPME method. 
The findings are presented in Figure 5 for the 5 target compounds. Hence, it can be deduced that the individual and total peak areas are reduced by the existence of water vapor within the headspace atmosphere confirming the former reports. It is found that the water molecules can deactivate the fiber surface by the blockage of the active site; thus, the suggested fiber is a decent adsorptive fiber to sample from the dried specimens.

\section{5. Desorption conditions.}

Desorption temperatures for the Nafion/SBA-15 nanocomposite SPME fiber were within the range of $200-270{ }^{\circ} \mathrm{C}$. The desorption time was also enhanced within the range of 1 $5 \mathrm{~min}$. The following steps are taken in the optimization procedure for selecting the optimal desorption circumstances defined by examining various times and temperatures. The values attained when desorbing all analytes from the fiber coating with minimal carryover effects to the following analysis are considered as the optimal values. The chromatograms were stabilized, and a desorption time of 2 minutes at $260^{\circ} \mathrm{C}$ was used to obtain the reproducible peak areas. Such values of desorption time and temperature were chosen for the consequent studies.

\section{6. HS-SPME of Nepeta haussknechtii Bornm.}

The feasibility of the proposed method was demonstrated by isolating the volatile compounds in Nepeta haussknechtii Bornm via the conventional hydrodistillation technique, for which the resulted are provided in Table 1. There is a consistency between these results and the results obtained by HS-SPME. Furthermore, their related contents by HS-SPME were also close to HD. It is indicated that there is no alteration in the Nepeta haussknechtii Bornm's chemical composition via the HD procedure. It is also indicated that the suggested technique is appropriate for analyzing the volatile compounds in medicinal plants. An extended time (at least 2 hours) is required for the conventional HD technique for isolating the volatile mixtures from medicinal plants. In the suggested technique, the isolation of volatile mixtures in the mentioned plant was obtained rapidly by heating the dry sample. Then, the isolated volatile compounds were simultaneously concentrated utilizing SPME. Owing to the concentration and extraction conducted in a single phase, only 30 minutes were needed to prepare the sample. Besides, only a small sample (2 g) with no solvent was required by HS-SPME. Thus, HSSPME is a rapid, solvent-free, simple, and low-cost technique for determining the medicinal plants' volatile ingredients. The precision of the method was obtained, three replicate analyses of the volatile constituents were conducted using HS-SPME at the optimal circumstances. The peak areas attained by replicate analyses were used to calculate the RSD values (Table 1). According to Table 1, the RSD values $(<13 \%)$ represent an acceptable HS-SPME precision.

Table 1. Constituents of the oil of Nepeta haussknechtii Bornm.

\begin{tabular}{|c|c|c|c|c|c|}
\hline No & Compounds & $\mathbf{R I}^{\mathbf{a}}$ & $\begin{array}{c}\text { (HD) } \\
\text { Area\%b }\end{array}$ & $\begin{array}{l}\text { SDME) } \\
\text { Area\%c }\end{array}$ & R.S.D. $\%^{d}$ \\
\hline 1 & $\alpha$-Thujene & 929 & 0.11 & 0.10 & 12.1 \\
\hline 2 & $\alpha$-Pinene & 935 & 2.37 & 2.01 & 9.6 \\
\hline 3 & Sabinene & 971 & 2.42 & 1.89 & 4.5 \\
\hline 4 & $\beta$-pinene & 978 & 5.73 & 5.17 & 3.9 \\
\hline 5 & Myrcene & 1000 & 3.11 & 1.97 & 10.2 \\
\hline 6 & $\alpha$-Phellandrene & 1002 & 0.65 & 0.48 & 10.1 \\
\hline 7 & $\delta$-3-Caren & 1010 & 1.12 & 0.19 & 9.5 \\
\hline 8 & $\alpha$-Terpinene & 1015 & 0.26 & 0.22 & 8.7 \\
\hline 9 & limonene & 1031 & 0.09 & 0.08 & 5.9 \\
\hline 10 & 1,8-cineole & 1037 & 26.11 & 24.27 & 7.3 \\
\hline
\end{tabular}




\begin{tabular}{|c|c|c|c|c|c|}
\hline No & Compounds & $\mathbf{R} \mathbf{I}^{\mathbf{a}}$ & $\begin{array}{c}(\mathrm{HD}) \\
\text { Area\% } \\
\end{array}$ & $\begin{array}{l}\text { SDME) } \\
\text { Area\%c }\end{array}$ & R.S.D.\% ${ }^{\mathrm{d}}$ \\
\hline 11 & Z- $\beta$-Ocimene & 1039 & 3.88 & 2.07 & 5.6 \\
\hline 12 & E- $\beta$-Ocimene & 1042 & 3.01 & 2.82 & 5.8 \\
\hline 13 & $\gamma$-Terpinene & 1058 & 4.15 & 3.61 & 8.3 \\
\hline 14 & n-Octanol & 1070 & 0.12 & 0.24 & 10.1 \\
\hline 15 & Meta-cresol & 1072 & 2.56 & 2.64 & 11.6 \\
\hline 16 & meta-cymenene & 1079 & 0.21 & 0.14 & 11.5 \\
\hline 17 & Terpinolene & 1080 & 0.14 & 0.10 & 12.4 \\
\hline 18 & linalool & 1104 & 0.10 & 0.06 & 5.9 \\
\hline 19 & Neo-allo ocimene & 1150 & 0.35 & 0.24 & 7.6 \\
\hline 20 & Cis-beta Terpineol & 1152 & 0.12 & 0.05 & 5.8 \\
\hline 21 & 3-Thujanol & 1163 & 0.24 & 0.21 & 4.9 \\
\hline 22 & Terpin-4-ol & 1172 & 0.18 & 0.14 & 7.8 \\
\hline 23 & Isomenthol & 1179 & 1.05 & 0.88 & 8.4 \\
\hline 24 & $\alpha$-terpineol & 1183 & 0.17 & 0.06 & 7.9 \\
\hline 25 & Nerol & 1223 & 0.13 & 0.11 & 8.2 \\
\hline 26 & Citronellol & 1229 & 0.07 & 0.14 & 9.2 \\
\hline 27 & Neral & 1241 & 0.12 & 0.10 & 6.4 \\
\hline 28 & Piperitone & 1250 & 0.07 & 0.14 & 7.6 \\
\hline 29 & $\alpha$-copaene & 1375 & 0.42 & 0.27 & 4.9 \\
\hline 30 & geranyl acetate & 1381 & 1.58 & 0.68 & 7.9 \\
\hline 31 & $\beta$-elemene & 1390 & 0.41 & 0.25 & 8.5 \\
\hline 32 & (Z)-jasmone & 1393 & 0.56 & 0.32 & 10.8 \\
\hline 33 & E-caryophyllene & 1423 & 2.31 & 1.75 & 10.6 \\
\hline 34 & $\alpha$-humulene & 1451 & 0.07 & 0.12 & 12.5 \\
\hline 35 & Germacrene D & 1478 & 5.27 & 4.16 & 10.2 \\
\hline 36 & Bicyclogermacrene & 1489 & 1.36 & 1.58 & 9.5 \\
\hline 37 & Zingiberene & 1494 & 2.15 & 2.08 & 7.5 \\
\hline 38 & (Z)- $\alpha$-bisabolene & 1508 & 1.36 & 1.24 & 7.2 \\
\hline 39 & $\delta$-cadinene & 1517 & 1.84 & 1.08 & 8.1 \\
\hline 40 & elemol & 1549 & 14.51 & 12.38 & 9.4 \\
\hline 41 & Spathulenol & 1575 & 2.64 & 2.81 & 6.7 \\
\hline 42 & caryophyllene oxide & 1582 & 1.30 & 0.76 & 9.3 \\
\hline
\end{tabular}

a) Retention indices (relative retention times normalize to closely eluting $n$-alkanes).

b) Relative area (peak area relative to total peak area) for hydrodistillation method.

c) Relative area (peak area relative to total peak area) for the SPME method.

\section{Conclusions}

In this study, the Nafion/SBA-15 nanocomposite's efficiency as fiber for HS-SPME (headspace solid-phase microextraction) of volatile compounds in a medicinal plant was initially assessed. The suggested method was used to identify 42 compounds in Nepeta haussknechtii Bornm. Compared to the conventional HD technique, HS-SPME/GC-MS is a rapid, simple, efficient and solvent-free technique for analyzing the essential oils in Nepeta haussknechtii Bornm other plants with low sample quantity. The presented technique is ecofriendly since no toxic solvent is utilized. Hence, no solvent peak exists in the chromatogram. This fiber has key advantages, including height temperature resistance, long durability, and firmness, which was utilized for the first time in analyzing the volatile compounds in medicinal plants.

\section{Funding}

This research received no external funding.

\section{Acknowledgments}

This paper has no acknowledgment. 


\section{Conflicts of Interest}

There is no conflict of interest with the authors.

\section{References}

1. Naeimi, A.; Payandeh, M.; Ghara, A.R.; Ghadi, F.E. In vivo evaluation of the wound healing properties of bio-nanofiber chitosan/polyvinyl alcohol incorporating honey and Nepeta dschuparensis. Carbohydrate Polymers 2020, 240, 116315, https://doi.org/10.1016/j.carbpol.2020.116315.

2. Sharifi-Rad, M.; Epifano, F.; Fiorito, S.; Álvarez-Suarez, J.M. Phytochemical analysis and biological investigation of Nepeta juncea Benth. different extracts. Plants 2020, 9, 646, https://doi.org/10.3390/plants9050646.

3. Debbabi, H.; Mokni, R.E.; Chaieb, I.; Nardoni, S.; Maggi, F.; Caprioli, G.; Hammami, S. Chemical Composition, Antifungal and Insecticidal Activities of the Essential Oils from Tunisian Clinopodium Nepeta subsp. nepeta and Clinopodium nepeta subsp. glandulosum. Molecules 2020, 25, 2137, https://doi.org/10.3390/molecules25092137.

4. Huang, S.; Tan, M.; Guo, F.; Dong, L.; Liu, Z.; Yuan, R.; Dongzhi, Z.; Lee, D.-S.; Wang, Y.; Li, B. Nepeta angustifolia CY Wu improves renal injury in HFD/STZ-induced diabetic nephropathy and inhibits oxidative stress-induced apoptosis of mesangial cells. Journal of ethnopharmacology 2020, 255, 112771, https://doi.org/10.1016/j.jep.2020.112771.

5. Hendi, R.; Piriyaei, M.; Asl, M.B.; Abolghasemi, M.M. Nanoporous Silica-Polypyrrole/SBA-15 as Fiber Coated in the Solid-Phase Microextraction for Determination of Salvia hydrangea DC. Essential Oil. Pharmaceutical Sciences 2018, 24, 235-239, https://doi.org/10.15171/PS.2018.34.

6. Piryaei, M.; Abolghasemi, M.M.; Karimi, B. Determination and analysis of volatile components from Thymus kotschyanus Boiss with a new solid-phase microextraction fibre and microwave-assisted hydrodistillation by periodic mesoporous organosilica based on alkylimidazolium ionic liquid. Phytochemical Analysis 2019, 30, 193-197, https://doi.org/10.1002/pca.2804.

7. Piryaei, M. Direct thermal desorption technique as a very fast, easy and low-cost method for analysis of volatile components compounds by gas chromatography with mass spectrometry. Separation Science Plus 2019, 2, 416-421, https://doi.org/10.1002/sscp.201900003.

8. Piryaei, M. Layered double hydroxide films on nanoporous anodic aluminum oxide/aluminum wire: a new fiber for rapid analysis of Origanum vulgare essential oils. Natural product research 2018, 32, 243-245, https://doi.org/10.1080/14786419.2017.1344656.

9. Majdafshar, M.; Piryaei, M.; Abolghasemi, M.M.; Rafiee, E. Polyoxometalate-based ionic liquid coating for solid phase microextraction of triazole pesticides in water samples. Separation Science and Technology 2019, 54, 1553-1559, https://doi.org/10.1080/01496395.2019.1572625.

10. Piryaei, M. The use of the headspace single drop microextraction and microwave distillation for determination of essential oil components of Salvia hydrangea DC. Natural product research 2020, 34, 2996-2999, https://doi.org/10.1080/14786419.2019.1598990.

11. Piryaei, M.; Babashpour-Asl, M. Carbon nanotube/layered double hydroxide nanocomposite as a fibre coating for determination the essential oils of Achillea eriophora DC with the headspace solid-phase microextraction. Natural product research 2019, 1-4, https://doi.org/10.1080/14786419.2019.1643856.

12. Piryaei, M.; Abolghasemi, M.M.; Karimi, B. Determination of the Volatile Components of Stachys Lavandulifolia with Periodic Mesoporous Organosilica as the Fiber Coating for Headspace Solid Phase Microextraction. Analytical and Bioanalytical Chemistry Research 2020, 8, 129-137, https://doi.org/10.22036/ABCR.2020.234359.1513.

13. Kang, H.; Kwon, S.H.; Lawler, R.; Lee, J.H.; Doo, G.; Kim, H.-T.; Yim, S.-D.; Jang, S.S.; Lee, S.G. Nanostructures of Nafion Film at Platinum/Carbon Surface in Catalyst Layer of PEMFC: Molecular Dynamics Simulation Approach. The Journal of Physical Chemistry C 2020, 124, 21386-21395, https://doi.org/10.1021/acs.jpcc.0c03651.

14. Li, Y.; Intikhab, S.; Malkani, A.; Xu, B.; Snyder, J. Ionic Liquid Additives for the Mitigation of Nafion Specific Adsorption on Platinum. ACS Catalysis 2020, 10, 7691-7698, https://doi.org/10.1021/acscatal.0c01243.

15. Flimban, S.G.; Hassan, S.H.; Rahman, M.M.; Oh, S.-E. The effect of Nafion membrane fouling on the power generation of a microbial fuel cell. international journal of hydrogen energy 2020, 45, 13643-13651, https://doi.org/10.1016/j.ijhydene.2018.02.097.

16. Carli, S.; Di Lauro, M.; Bianchi, M.; Murgia, M.; De Salvo, A.; Prato, M.; Fadiga, L.; Biscarini, F. WaterBased PEDOT: Nafion Dispersion for Organic Bioelectronics. ACS Applied Materials \& Interfaces 2020, 12, 29807-29817, https://doi.org/10.1021/acsami.0c06538.

17. Karthika, A.; Rosaline, D.R.; Inbanathan, S.; Suganthi, A.; Rajarajan, M. Fabrication of Cupric oxide decorated $\beta$-cyclodextrin nanocomposite solubilized Nafion as a high performance electrochemical sensor for 1-tyrosine detection. Journal of Physics and Chemistry of Solids 2020, 136, 109145, https://doi.org/10.1016/j.jpcs.2019.109145.

https://biointerfaceresearch.com/ 
18. Abolghasemi, M.M.; Piryaei, M.; Imani, R.M. Deep eutectic solvents as extraction phase in headspace singledrop microextraction for determination of pesticides in fruit juice and vegetable samples. Microchemical Journal 2020, 158, 105041, https://doi.org/10.1016/j.microc.2020.105041.

19. Abolghasemi, M.M.; Habibiyan, R.; Jaymand, M.; Piryaei, M. A star-shaped polythiophene dendrimer coating for solid-phase microextraction of triazole agrochemicals. Microchimica Acta 2018, 185, 1-6, https://doi.org/10.1007/s00604-017-2639-8.

20. Abolghasemi, M.M.; Amirifard, H.; Piryaei, M. Bio template route for fabrication of a hybrid material composed of hierarchical boehmite, layered double hydroxides $(\mathrm{Mg}-\mathrm{Al})$ and porous carbon on a steel fiber for solid phase microextraction of agrochemicals. Microchimica Acta 2019, 186, 1-7, https://doi.org/10.1007/s00604-019-3782-1.

21. Mabuchi, T.; Huang, S.-F.; Tokumasu, T. Dispersion of Nafion Ionomer Aggregates in 1-Propanol/Water Solutions: Effects of Ionomer Concentration, Alcohol Content, and Salt Addition. Macromolecules 2020, 53, 3273-3283, https://doi.org/10.1021/acs.macromol.9b02725.

22. Luo, Y.; Yang, Q.; Nie, W.; Yao, Q.; Zhang, Z.; Lu, Z.-H. Anchoring IrPdAu nanoparticles on NH2-SBA15 for fast hydrogen production from formic acid at room temperature. ACS applied materials \& interfaces 2020, 12, 8082-8090, https://doi.org/10.1021/acsami.9b16981.

23. Betiha, M.; Moustafa, Y.; El-Shahat, M.; Rafik, E. Polyvinylpyrrolidone-Aminopropyl-SBA-15 schiff Base hybrid for efficient removal of divalent heavy metal cations from wastewater. Journal of Hazardous Materials 2020, 397, 122675, https://doi.org/10.1016/j.jhazmat.2020.122675.

24. Shahed, G.V.; Taherian, Z.; Khataee, A.; Meshkani, F.; Orooji, Y. Samarium-impregnated nickel catalysts over SBA-15 in steam reforming of CH4 process. Journal of Industrial and Engineering Chemistry 2020, 86, 73-80, https://doi.org/10.1016/j.jiec.2020.02.012. 